\title{
PERFIL DE ESTUDANTES DO PROEJA TÉCNICO EM COMÉRCIO DO INSTITUTO FEDERAL FARROUPILHA - MUNICÍPIO DE JÚLIO DE CASTILHOS/RS EM 2012
}

http://dx.doi.org/10.5902/2318133817060

\author{
Aline Sobreira Bezerra \\ Universidade Federal de Santa Maria, Brasil. \\ Anne y Castro Marques \\ Universidade Federal do Pampa - campus Itaqui, Brasil. \\ Andréia Cirolini \\ Universidade Federal de Santa Maria - Udessm, Brasil. \\ Eloi Paulus \\ Universidade Federal de Santa Maria, Brasil. \\ Débora Teixeira de Mello \\ Universidade Federal de Santa Maria, Brasil.
}

\section{Resumo}

O presente trabalho teve como objetivo identificar o perfil dos estudantes do Proeja vinculados ao curso Técnico em Comércio do Instituto Federal Farroupilha - município de Júlio de Castilhos/RS. Foi realizada uma pesquisa de caráter quanti-qualitativo e como instrumento foi utilizado um questionário com 15 perguntas fechadas, as quais englobaram aspectos socioeconômicos, trajetória familiar e escolar, avaliação sobre estudos, trabalho e dificuldades, e uma entrevista com a coordenadora do curso. A maioria dos investigados disse ter investido no Proeja com a expectativa de inserção profissional e como forma de concluir o ensino médio. Consideram ótima a qualidade de ensino da instituição e caracterizam os professores como preocupados e dedicados. A maioria têm pretensões de cursar um curso de nível superior e de continuar a realizar cursos na área de estudo. Conclui-se que a profissionalização pelo Proeja tem o desafio de contribuir para a inclusão desses indivíduos no mundo do trabalho e de manter o acesso aos variados bens culturais.

Palavras-chave: educação de jovens e adultos, educação profissionalizante, inclusão social.

1 Este trabalho foi resultado de uma pesquisa realizada no IFFarroupilha - campus Júlio de Castilhos/RS, como requisito parcial à obtenção do grau de licenciatura no Programa Especial de Graduação em Formação de Professores para a Educação Profissional da Universidade Federal de Santa Maria.

\begin{tabular}{l|l|l|l|l|r|} 
Regae: Rev. Gest. Aval. Educ. & Santa Maria & v. 4 & n. 8 & Jul./dez. 2015 & p. $41-50$
\end{tabular} 


\title{
PROFILE OF STUDENTS' PROEJA TECHNICIAN AT TRADE OF INSTITUTO FEDERAL FARROUPILHA COUNTY OF JÚLIO DE CASTILHOS/RS IN 2012
}

\begin{abstract}
This study aimed to identify the profile of the Proeja students'. Was performed a survey of quantitative and qualitative character and as an instrument was used a questionnaire with 15 closed questions, which encompassed socioeconomic, family and school history, review of studies, work and difficulties, and an interview with the coordinator of the course. Most investigated invests in Proeja expecting to work in the area, and secondly as a way to complete high school. Consider the optimal teaching quality of the institution, and characterize teachers as concerned and dedicated. Most have aspirations of attending a higher level and to continue to provide courses in the study area. It was concluded that the professionalization by Proeja has the challenge of contributing to the inclusion of individuals of diversified capital in the world of work and to maintain access to the varied cultural heritage.

Key-words: young and adults education, professional education, social inclusion.
\end{abstract}




\section{Introdução}

consolidação do modelo econômico globalizado repercute no perfil dos A profissionais solicitados pelo mercado de trabalho, bem como no perfil do estudante que frequenta o Programa Nacional de Integração da Educação Profissional com a Educação Básica, na modalidade de Educação de Jovens e Adultos Proeja.

O Proeja, um programa de inclusão de jovens e adultos no sistema público de educação profissional, tem como finalidade a profissionalização, a qual contribui para a inserção desses indivíduos no mundo do trabalho pela via formal, tendo em vista que este programa faz parte de um projeto nacional de desenvolvimento. Para abordar o tema serão utilizados como referência materiais do Ministério da Educação, incluindo a Lei de Diretrizes e Bases, os trabalhos de Azevedo e Lima (2011) e de Franzoi et al (2010), e os trabalhos de Gatti (2001) e André (2001) sobre pesquisa qualitativa.

Esta pesquisa teve como sujeitos os estudantes do Proeja do curso Técnico em Comércio do Instituto Federal Farroupilha - IFF - localizado no município de Júlio de Castilhos/Rio Grande do Sul.

O presente trabalho de pesquisa se desenvolveu no âmbito do Programa Especial de Graduação para Formação de Professores para a Educação Profissional, como requisito para a conclusão do curso. Nosso objetivo foi contribuir para o ensino profissional, identificando como se articulam os principais condicionantes para acesso e permanência dos alunos no Programa Nacional de Integração da Educação Profissional com a Educação Básica, na modalidade de Educação de Jovens e Adultos.

\section{A educação de jovens e adultos no Brasil}

A educação é um direito e uma das condições essenciais para que os cidadãos tenham acesso ao conjunto de bens e serviços disponíveis na sociedade brasileira (Brasil, 1988; 1996). Embora as leis nacionais garantam o direito à educação, a inclusão escolar depende de uma série de variantes para ser efetiva, como acesso, permanência, qualidade, gratuidade, pluralidade, ensino e aprendizagem. Neste contexto, lembra-se da questão da evasão escolar, ou seja, o abandono da escola, que, por sua vez, é o abandono dos próprios sistemas de ensino no Brasil (Azevedo; Lima, 2011). Com a evasão, muitos alunos não concluem as etapas de ensino na idade adequada, o que dificulta sua inserção na vida social e econômica.

Com o intuito de minimizar essa defasagem escolar, a Educação de Jovens e Adultos - EJA -, de acordo com a lei n. 9.394/96, é uma modalidade da educação básica nas etapas do ensino fundamental e ensino médio. Segundo o artigo 37 desta lei, a EJA destina-se àqueles que não tiveram acesso ou continuidade de estudos no ensino fundamental e ensino médio na idade própria, de forma gratuita. Além disto, o poder público deve viabilizar e estimular o acesso e a permanência do trabalhador na escola, mediante ações integradas e complementares entre si (Brasil, 2000, 2006). Na EJA se trabalha, basicamente, com sujeitos distantes do sistema, com atributos acentuados em consequência de alguns fatores adicionais, tais como raça, etnia, gênero, idade, fatores sociais, entre outros (Brasil, 2007). 
Em relação à normatização da educação de jovens e adultos, a resolução n. 3 , de 15 de junho de 2010, instituiu as diretrizes operacionais nos aspectos relativos à duração dos cursos e idade mínima para ingresso, certificação nos exames e a utilização da educação à distância aplicada à EJA. Para a inserção nesta modalidade de ensino o aluno deve ter acima de quinze anos no nível de conclusão do ensino fundamental e acima de dezoito anos no nível de conclusão do ensino médio (Brasil, 2010).

Outro aspecto relevante é que a educação de jovens e adultos deve ser articulada, preferencialmente, com a educação profissional. Nesta perspectiva, a partir do decreto $\mathrm{n}$. 5.478/05, posteriormente substituído pelo decreto n. 5.840/06, foi criado o Programa Nacional de Integração da Educação Profissional com a Educação Básica na Modalidade de Educação de Jovens e Adultos - Proeja.

De acordo com o decreto n. 5840/06, os cursos do Proeja podem ser oferecidos, na modalidade de educação de jovens e adultos, como: educação profissional técnica integrada ou concomitante ao ensino médio; formação inicial e continuada ou qualificação profissional integrada ou concomitante ao ensino fundamental; e formação inicial e continuada ou qualificação profissional integrada ou concomitante ao ensino médio (Brasil, 2010).

Os principais programas governamentais relacionados ao EJA/Proeja em vigência são o Programa de Apoio ao Ensino e à Pesquisa Científica e Tecnológica em Educação Profissional Integrada à Educação de Jovens e Adultos - Proeja Capes/Setec - e o Programa Nacional de Integração da Educação Profissional com a Educação Básica na Modalidade de Educação de Jovens e Adultos, Formação Inicial e Continuada com o Ensino Fundamental - Proeja FIC. O Proeja Capes/Setec tem como objetivo estimular a produção de pesquisas científicas e tecnológicas e a formação de recursos humanos pósgraduados em educação profissional integrada à educação de jovens e adultos, enquanto - Proeja FIC busca contribuir para melhoria e ampliação da oferta de formação para trabalhadores (Brasil, 2011; Capes, 2011).

\section{Procedimentos metodológicos}

Visando identificar o perfil dos estudantes no Proeja vinculados ao curso Técnico em Comércio do Instituto Federal Farroupilha - município de Júlio de Castilhos/RS, foi realizada uma pesquisa quanti-qualitativa (André, 2001; Gatti, 2001; Franzoi et al., 2010). Visando este objetivo, foi aplicado um questionário, o qual englobou aspectos socioeconômicos, trajetória familiar e escolar, avaliação sobre os estudos, trabalho e dificuldades dos estudantes. Por meio do questionário foram também investigadas características dos alunos, tais como: sexo, idade, estado civil, período de afastamento escolar, renda familiar, expectativa em relação ao curso, percepção da qualidade de ensino e dos professores, atividades extraclasse e pretensões de ensino continuado.

Os dados foram levantados no primeiro semestre de 2012, no Instituto Federal Farroupilha, campus Júlio de Castilhos, no curso Técnico Proeja Comércio, nas turmas do $1^{\circ}, 3^{\circ}$ e $5^{\circ}$ semestre, sendo entrevistados 62 alunos.

Todos os alunos matriculados no curso foram convidados a participar da pesquisa. Anteriormente à aplicação do questionário, os sujeitos receberam e assinaram o termo de consentimento livre e esclarecido. 
Com a finalidade de levantar informações acerca do Proeja Comércio e de esclarecer alguns pontos observados durante a aplicação do questionário, foi realizada uma entrevista com a coordenadora do curso, abordando os seguintes aspectos: organização do curso, pontos fortes, fragilidades, indicadores e projetos referentes ao Proeja na Instituição.

\section{Resultados e discussão}

O Proeja Comércio está organizado em áreas do conhecimento: linguagens, códigos e suas tecnologias; ciência da natureza; matemática e suas tecnologias; ciências humanas e suas tecnologias; comércio e trabalho; práticas profissionais integradas e atividades complementares. O curso é distribuído ao longo de três anos, com carga horária total de 2.400 horas (Brasil, 2012).

Em relação ao perfil dos estudantes os dados mostraram que o curso é frequentado em sua maioria por mulheres, correspondendo a $71 \%$ do total dos alunos do curso. A grande inserção do sexo feminino no mundo do trabalho, nos últimos cinquenta anos, de acordo com IBGE (2002), é um dos fatores marcantes ocorridos na sociedade brasileira e que pode justificar os dados encontrados nesse estudo.

Este aumento da participação feminina é explicado por uma combinação de fatores econômicos e culturais. Primeiro, o avanço da industrialização transformou a estrutura produtiva, a continuidade do processo de urbanização e a queda das taxas de fecundidade, proporcionaram um aumento das possibilidades das mulheres encontrarem postos de trabalho na sociedade.

A avaliação dos dados permitiu a percepção de elementos referentes ao perfil de idade dos estudantes do Proeja Comércio. A análise da tabela 1 demonstra que $37 \%$ dos estudantes têm até 25 anos. Em contrapartida, $45 \%$ dos estudantes apresentam idade superior a 38 anos. No estudo de Franzoi et al (2010), realizado no Rio Grande do Sul, a maioria dos estudantes frequentando o Proeja apresentavam idade inferior a 30 anos (56\%), resultado este divergente do nosso estudo.

Tabela 1 -

Faixa etária por semestre dos alunos no Proeja Comércio.

\begin{tabular}{l|c|c|c|c|c}
\hline & $\begin{array}{c}1^{\circ} \text { semestre } \\
(2 \mathrm{~A})\end{array}$ & $\begin{array}{c}1^{\circ} \text { semestre } \\
(2 \mathrm{~B})\end{array}$ & $3^{\circ}$ semestre & $5^{\circ}$ semestre & Total de alunos \\
\hline Até 20 anos & $18 \%$ & $5 \%$ & $58 \%$ & $0 \%$ & $19 \%$ \\
\hline $21-25$ anos & $14 \%$ & $0 \%$ & $17 \%$ & $75 \%$ & $18 \%$ \\
\hline $26-31$ anos & $5 \%$ & $0 \%$ & $8 \%$ & $0 \%$ & $3 \%$ \\
\hline $32-37$ anos & $14 \%$ & $25 \%$ & $8 \%$ & $0 \%$ & $15 \%$ \\
\hline$>38$ anos & $50 \%$ & $70 \%$ & $8 \%$ & $25 \%$ & $45 \%$ \\
\hline Total & $100 \%$ & $100 \%$ & $100 \%$ & $100 \%$ & $100 \%$ \\
\hline
\end{tabular}

Fonte: Dados da pesquisa.

O perfil dos alunos, quanto ao seu estado civil, apresenta-se equilibrado, com $44 \%$ dos alunos declarados solteiros e $40 \%$ casados ou em união estável, $8 \%$ separados e $8 \%$ viúvos. 
Um dos dados mais significativos refere-se à quantidade de alunos que permaneceram afastados da escola por determinado período: $77 \%$ do total de alunos. Destes, $77 \%$ ficaram afastados por mais de 11 anos, $4 \%$ de 6 a 10 anos e $19 \%$ até 5 anos. Esta distribuição vem ao encontro dos dados da divisão etária das turmas, compostas por $45 \%$ de alunos com idade acima de 38 anos.

Segundo dados do IBGE, relativos ao Censo 2010, o rendimento médio mensal de todos os trabalhos das pessoas ocupadas com rendimento de trabalho foi de $R \$ 1.345,00$ contra $R \$ 1.275,00$ em 2000, um ganho real de 5,5\%. Essa informação apenas foi observada em $13 \%$ dos entrevistados, os quais informaram renda acima de dois salários mínimos, correspondendo ao valor atual de $\mathrm{R} \$ 1.464,72$, baseados no valor do salário mínimo regional do Rio Grande do Sul do Comércio de $\mathrm{R} \$ 732,36$ (2012).

A tabulação dos dados mostrou que a maioria dos investigados (42\%) investe no Proeja com a expectativa de inserção profissional e, segundo lugar, como forma de concluir o ensino médio (35\%). Quanto à qualidade de ensino oferecido na instituição, $55 \%$ dos entrevistados considera ótima, bem como caracterizam os professores como preocupados e dedicados com relação ao ensino (53\%).

Figura 1 -

Percepção dos alunos com relação aos professores do curso Proeja Comércio.

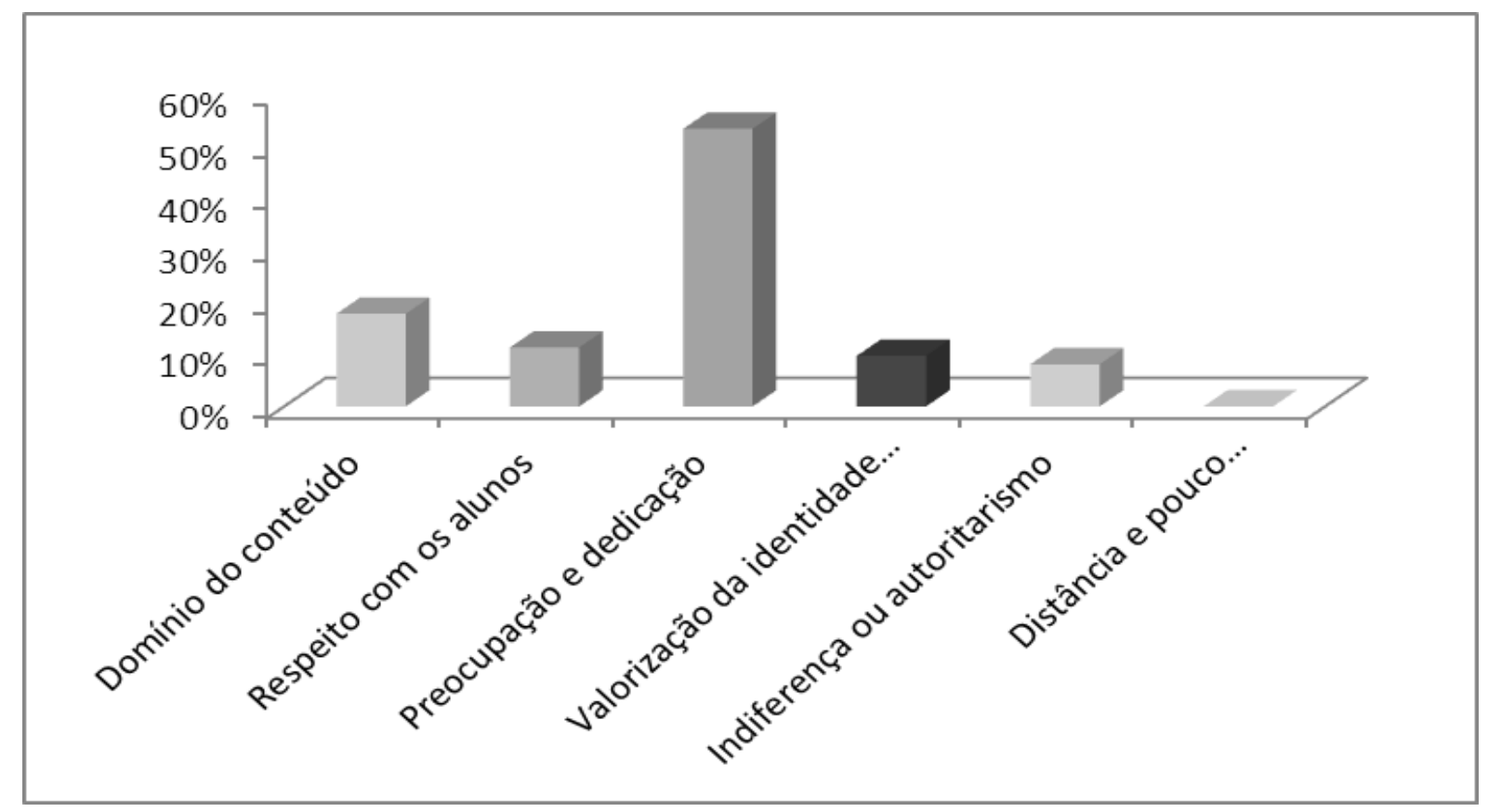

Fonte: Dados da pesquisa.

Observamos que os professores do Proeja foram avaliados como preocupados e dedicados pela maioria dos alunos, porém, o mesmo não foi observado por Franzoi et al (2010). Segundo os autores, os alunos alegaram estar desmotivados em frequentar o Proeja devido à resistência dos professores em atuar nesta modalidade de ensino. A indiferença e o autoritarismo foi considerado por $8 \%$ dos estudantes, sendo alegado como fator preponderante na evasão escolar a falta de experiência dos professores em lidar com alunos de mais idade. Nesse contexto, com referência à formação profissional do 
professor, o excesso de trabalho, a falta de experiência com alunos adultos e a não concordância com o modelo curricular estão entre os motivos apontados pelos alunos com causadores da resistência dos docentes ao programa.

Em relação ao vínculo empregatício, $73 \%$ dos alunos relataram já ter exercido alguma função com carteira assinada. Durante a realização da pesquisa $84 \%$ dos alunos estavam trabalhando, sendo o motivo sustentar a família o mais frequente (34\%). Nessa mesma questão um dado salientado na amostragem por turma é que $100 \%$ dos alunos do quinto semestre trabalham concomitantemente com os estudos. No estudo realizado por Franzoi et al (2010), 72\% dos estudantes declararam estar trabalhando. Segundo os autores, este dado não significa que os demais não tenham sido trabalhadores ou possam estar à procura de trabalho.

Com relação à evasão escolar, Azevedo e Lima (2011), citam que um estudo com alunos na faixa etária de 15 a 17 anos no Brasil, observou que quatro foram os motivos para justificar esse fato: trabalho, falta de acesso, trabalho doméstico entre mulheres, família e déficit de cultura escolar. Em nossa pesquisa observamos um maior público masculino dando continuidade ao curso em relação ao público feminino.

Analisando-se o número de alunos quanto ao fator evasão escolar, observamos que na turma ingressante no ano de 2010, 5 semestre, dos 30 alunos matriculados, 13 evadiram, 43,33\%, e 13 concluíram o curso em 2012, enquanto que quatro deles estão em curso em função de reprovação. Na turma de 2011, 3ำ semestre, dos 30 matriculados, 16 evadiram, 53,33\%, e 11 estão matriculados no último ano, enquanto que três são repetentes no $2^{\circ}$ ano. Já na turma ingressante no ano de 2012, $1^{\circ}$ semestre, houve matrícula de 60 alunos, dos quais 17 - 28,33\% - se evadiram e 43 estão matriculados no $2^{\circ}$ ano.

$\mathrm{Na}$ instituição e no curso pesquisado, observou-se maior evasão dos alunos mais jovens. Entre o grupo da maior idade, a evasão ocorreu em função de problemas de saúde, família e em função do auxílio financeiro. Até o ano de 2012 todos os ingressantes no Proeja recebiam bolsa auxílio, com as atuais mudanças governamentais houve suspensão da bolsa a todos os alunos ingressantes, no entanto, disponibilizou-se uma assistência estudantil aos alunos de baixa renda.

Alguns dos motivos apontados para a evasão escolar por outros autores são dificuldades nas disciplinas técnicas, dificuldades de aprendizagem, dificuldade em conciliar trabalho e escola, falta de incentivo dos professores, problemas familiares, problemas com transporte e cansaço (Debiaso, 2010; Bonfim; Arruda, 2012).

Com relação ao sucesso e permanência dos alunos no Proeja, Franzoi et al (2010) encontraram um valor de evasão em torno de $23 \%$. Os autores observaram que a evasão varia de acordo com o curso e a localidade, variando de $12 \%$ no curso de Instalação e Manutenção Industrial do Colégio Técnico Industrial de Santa Maria, a 50\% no curso de Informática, do Instituto Federal Farroupilha Sul - campus Charqueadas.

A maioria dos alunos trabalha, podendo ser este um motivo para que haja o abandono dos estudos. Além disso, observamos que dos alunos ingressantes no Proeja $50 \%$ estão na faixa etária acima de 38 anos, enquanto os alunos frequentando o último semestre do curso são compostos por maioria, 75\%, de jovens até 25 anos. Note-se que $77 \%$ desses alunos relataram estar há mais de onze anos sem estudar. A idade e o 
tempo de afastamento dos estudos são fatores que contribuem no aumento de dificuldades de aprendizagens e, por consequência, constitui-se em um fato que contribui para a desistência do curso, conforme apontam os estudos de Debiaso (2010) e Bonfim e Arruda (2012).

No que se refere às dificuldades de permanência dos alunos nos cursos ainda pode ser destacado: o desconhecimento do público alvo, a inadequação inicial dos currículos e horários incompatíveis com a realidade dos alunos (Franzoi et al, 2010).

Conforme relatado pela coordenadora do Proeja Comércio, o projeto pedagógico do curso teve sua primeira versão elaborada por um grupo de servidores envolvidos com as questões do Proeja. É possível salientar que as dificuldades anteriormente citadas por outros autores em suas pesquisas também foram em determinados momentos observados em nosso estudo, apesar de toda a preocupação em evitar todos os transtornos da evasão escolar.

Ao ser questionada sobre os pontos fortes do curso, a coordenadora do Proeja Comércio relatou o seguinte:

"Os pontos fortes do programa são: currículo integrado articulando áreas
do conhecimento com momentos de produções compartilhadas entre os
estudantes; envolvimento com os cursos de licenciatura no campus, por
meio de observações nas salas de aula, estágios e pesquisas; troca de
professores que se reúnem quinzenalmente para planejar atividades
integradas, focando a avaliação, andamento do curso e alternativas para
atendimento aos alunos; bolsas (auxílio permanência, de pesquisa e
extensão); e participação dos alunos em eventos. Uma meta a ser buscada
é a Pedagogia da Alternância, onde o aluno permanece um semestre no
campus e dois semestres em trabalhos junto a comunidade. Com relação
às melhorias do programa, é necessário um maior envolvimento dos
gestores com o curso e um reconhecimento dos docentes frente a esta
modalidade de ensino."

Por fim, dos alunos que permanecem no programa, 92\% têm pretensões de cursar um nível superior e $87 \%$ de continuar a realizar cursos na área de estudo. Assim, a verticalização do ensino deve ser focada pela instituição para receber os alunos egressos do Proeja que pretendem continuar seus estudos na área em questão.

Em relação às melhorias necessárias para o programa, um dos desafios a serem enfrentados é investir na formação dos professores para a educação profissional, culminando em maior permanência dos alunos no programa.

\section{Considerações finais}

Os dados apresentados nesse artigo reforçam o Proeja como um programa de inclusão de jovens e adultos no sistema público de educação profissional, com a finalidade de profissionalização e inclusão social, tendo em vista que esse programa faz parte de um projeto nacional de desenvolvimento.

A necessidade de verticalização do ensino e um maior investimento no programa devem ser focados na garantia de uma maior permanência dos alunos. Dessa forma, a profissionalização por meio do Proeja tem o desafio de contribuir para a inclusão desses indivíduos de capital social diversificado no mundo do trabalho pela via formal, com vistas 
a manter o acesso aos mais variados bens culturais e direito constitucionais do cidadão brasileiro.

\section{Referências}

ANDRÉ, Marli. Pesquisa em educação: buscando rigor e qualidade. Cadernos de Pesquisa, n. 113, 2001, p. 51-64.

AZEVEDO, Clayte de Paula; LIMA, Ezilda Soares. A evasão escolar no Proeja do CefetMT: existência e visão. Educação Profissional: Ciência e Tecnologia, v. 4, n. 2, 2011, p. 79-88.

BONFIM. Silvana Vanessa Martins da Silva; ARRUDA, Maria da Conceição Calmon. $A$ questão da evasão no Proeja: um estudo de caso no IF baiano campus Guanambi. ENCONTRO NACIONAL DE DIDÁTICA E PRÁTICAS DE ENSINO, 16, 2012. Anais ... Campinas: Unicamp, 2012.

BRASIL. Constituição da República Federativa do Brasil de 1988. 1988. Disponível em <http://www.planalto.gov.br/ccivil_03/constituicao/constituicaocompilado.htm>. Acesso em 30 nov. 2012.

BRASIL. Lei de diretrizes e bases da educação nacional, Lei no 9.394, de 20 de dezembro de 1996. 1996. Disponível em <http://www.planalto.gov.br/ccivil 03/leis/L9394.htm>. Acesso em 30 nov. 2012.

BRASIL. MINISTÉRIO DA EDUCAÇÃO. Ações Proeja 2011. Disponível em $<$ http://portal.mec.gov.br/index.php?option=com_content\&view=article\&id=12288\&ltemid= 562>. Acesso em 17 jan. 2013.

BRASIL. MINISTÉRIO DA EDUCAÇÃO. Projeto pedagógico do Curso Técnico em Comércio, na modalidade de Educação de Jovens e Adultos - Proeja, campus Júlio de Castilhos. Júlio de Castilhos: UFSM, 2012.

BRASIL. Proeja: Programa nacional de integração da educação profissional com a educação básica na modalidade de educação de jovens e adultos. Brasília: MEC, 2007.

BRASIL. Relatório do programa estratégico do Proeja. Brasília: MEC, 2007.

BRASIL. Parecer CNE/CEB 11/2000. Brasília: Brasil, 2000.

BRASIL. INSTITUTO BRASILEIRO DE GEOGRAFIA E ESTATÍSTICA (IBGE). Disponível em: <http://www.ibge.gov.br/censo2010 >. Acesso em: 05 jan. 2013.

COORDENAÇÃO DE APERFEIÇOAMENTO DE PESSOAL DE NÍVEL SUPERIOR. CAPES. Programa de apoio ao ensino e à pesquisa científica e tecnológica em educação profissional integrada à educação de jovens e adultos: Proeja-Capes/Setec. 2011. Disponível em <http://www.capes.gov.br/bolsas/programas-especiais/PROEJA>. Acesso em 17 jan. 2013.

DEBIASIO, Flávia de Jesus Mendes. Acesso, permanência e evasão dos cursos do Proeja em instituições de ensino em Curitiba - PR. Curitiba: UTFPR, 2010. $128 f$. Dissertação (mestrado em Tecnologia). Universidade Tecnológica Federal do Paraná.

FRAZOI, Naira Lisboa; HYPOLLITO, Alvaro Moreira; FISCHER, Maria Clara; DEL PINO, Mauro; SANTOS, Simone Valdete dos. Escola, saberes e trabalho: a pesquisa do PROEJA no Rio Grande do Sul. Educação \& Realidade, v. 35, n. 1, 2010, p. 167-186.

INSTITUTO FEDERAL FARROUPILHA - CAMPUS JULIO DE CASTILHOS. Projeto pedagógico do curso Técnico em Comércio - modalidade educação de jovens e adultos:

\begin{tabular}{|l|l|l|l|l|r|}
\hline Regae: Rev. Gest. Aval. Educ. & Santa Maria & v. 4 & n. 8 & Jul./dez. 2015 & p. 41-50
\end{tabular}


Proeja. Disponível em <http://www.jc.iffarroupilha.edu.br/site/midias/arquivos/20118221159 33140ppc tec comercio - reitoria.pdf>. Acesso em 25 nov. 2012.

GATTI, Bernardete. Angelina. Implicações e perspectivas da pesquisa educacional no Brasil contemporâneo. Cadernos de Pesquisa, n. 113, 2001, p. 65-81.

Aline Sobreira Bezerra é professora no curso de Nutrição da Universidade Federal de Santa Maria.

Endereço: Av. Independência, 3751/118 - 98300-000 - Palmeira das Missões - RS Brasil.

E-mail: alinecelo@hotmail.com.

Anne Y Castro Marques é professora no curso de Nutrição da Universidade Federal do Pampa, Campus Itaqui.

Endereço: Rua Luiz Joaquim de Sá Britto, s/n - 97650000 - Itaqui - RS - Brasil.

E-mail: annezita@gmail.com.

Andréia Cirolini é professora no curso Superior de Tecnologia em Agronegócio da Universidade Federal de Santa Maria - Unidade Descentralizada de Educação Superior - Silveira Martins.

Endereço: Rua Francisco Guerino, 407 - 97195000 - Silveira Martins - RS - Brasil.

E-mail: deiacirolini@yahoo.com.br.

Eloi Paulus é doutor em Engenharia Florestal da Universidade Federal de Santa Maria.

Endereço: Avenida Roraima, 1000 - prédio 44 - sala 5255 - 97105-900 - Santa Maria - RS - Brasil.

E-mail: epaulus2000@yahoo.com.br.

Débora Teixeira de Mello é professora no Centro de Educação da Universidade Federal de Santa Maria.

Endereço: Avenida Roraima, 1000 - 97105-900 - Santa Maria - RS - Brasil.

E-mail: deboramellors@yahoo.com.br.

Recebido em 25 de fevereiro de 2015.

Aceito em 15 de abril de 2015. 